\title{
Evaluation on economic sustainability of Yunnan province from energy metabolism perspective
}

\author{
Linlin Liang* \\ International Business School \\ Yunnan University of Finance and Economics \\ Kunming, China \\ 279653205@qq.com
}

\author{
Liu Yang \\ International Business School \\ Yunnan University of Finance and Economics \\ Kunming, China \\ Liu9218@vip.qq.com
}

\begin{abstract}
Under the strategy of The Belt and Road, the intensified contradiction of energy supply and demand lead to more resource constraints and environmental pressures in the development of economy. It constitutes a big threat to the sustainable development of Yunnan province. Based on the development of sustainable economy, this paper analyzed energy metabolism of each industry of Yunnan province with the methods of multi-scale integrated analysis of societal metabolism (MSIASM) to evaluate the sustainability of economy in Yunnan province.
\end{abstract}

Keywords-Evaluation; Economic; Sustainability; Energy metabolism; MSIASM

\section{INTRODUCTION}

Energy is the engine of the national economy and the material foundation of human civilization. It's also one of the prerequisites to realize modernization of society. The consumption of per unit of GDP is high and presents gradually rising trend in recent years in Yunnan province. With low efficiency of energy utilization, it must have adverse effect on the sustainable development of economy in the long run. To solve the problem of energy consumption and the relationship between energy and economic development, it is likely to solve a series of major issues of economic development, such as scale, speed, quality, social sustainable development, etc. Therefore, how to face energy problems and solve the issue of Yunnan province with systematic and in-depth study of is of the utmost theoretical and practical needs.

\section{TheORETICAL FrameWORK OF ENERGy MEtABOLISM}

\section{A. The oretical framework of enery metabolism}

In the early 1990s, Italian scholar Giampietro and Japanese scholars Mayumi put forward MSIASM together to Comprehensive analysis the development of social economy and sustainability [1]. From the perspective of research on regional sustainable development, MSIASM belong to the area of energy metabolism. Social metabolism is the metabolism of material and energy in socio-economic system, multi-scale integrated analysis of societal metabolism focus on the metabolism of energy, especially metabolism of

\footnotetext{
* Corresponding author
}

exosomatic energy. MSIASM reflected the concept of bioeconomics that put forward by Georgescu-Roegen[2][3], Mayumi [4-5], Mayumi and Gowdy[6]-[8].

\section{B. Description of variables}

MSIASM investigate the sustainable development situation of social, economic and environmental through some index (such as human activities time, exosomatic energy throughput, value added, exosomatic metabolic rate, economic labor productivity, etc).

\section{1) Human activities}

Human activity (HA) refers to the amount of human activity time in social system, represented by the product of the population and the activity time. Including the total amounts of human activities, department of human activity and social spending of human activity. Societal overhead of human activities (SOHA) is refers to the ratio between social human activity time and production inputs and support costs

\section{2) Exosomatic energy throughput}

Exosomatic energy throughput can distinguish the metabolism of human body metabolism of social and economic system and economic production activities and metabolism.

a) Exosomatic energy throughput in the socio-economic systems

Total exosomatic energy throughput (TET) refers to the whole metabolism of exosomatic energy throughput in the socio-economic systems in one year. ET1, ET2, ET3 represent exosomatic energy throughput in primary industry, secondary industry and tertiary industry in turn.

\section{b) Exosomatic metabolic rate}

Exosomatic metabolic rate (EMR) is an important parameter in study of society metabolism. EMR refers to the average hourly metabolic quantity of exosomatic energy in human activity. This quantity will improve with the development of the society.

\section{3) The relevant parameter of value added throughput}


Value added is presented by the total GDP of whole system and the GDP of per department. At the same time, it can reflect the economic development situation.

\section{PROBLEM ANALYSIS}

Currently, Yunnan Province kept good development trend. With the One belt One Road Strategy proposed by Chinese government, Yunnan became the important passage to develop the economic cooperation between China and South-east Asia and South Asia. Yunnan Province is abundant with energy resources which including hydroenergy, wind energy, solar energy and so on.

With the development of Yunnan Province, the energy demand is increasing. According to the statistical data, energy consumption amount and structure appeared the following characteristics:

1) The energy consumption amount is quickly increasing.

Energy consumption increased from 2640.55 tons of standard coal in 1995 to 11316.95 tons of standard coal in 2015 .

2) Energy consumption is larger in Secondary industry.

The energy consumption in Secondary industry is $70 \%$ of the whole consumption especially in the period of 2002-2006.

3) Energy consumption in tertiary industry is gradually increasing.

In summary, the Secondary Industry is the main energy consumption body and has great effect on the increasing ratio.

\section{A. Data source}

Based on the data from 1995 to 2015 to study the energy metabolism in Yunnan provinc. All of the data from the Statistical Yearbook of the Yunnan 2016 and the Energy Statistics Yearbook 2016 of Yunnan.

\section{B. Calculation results of parameters}

\section{1) Human activity time}

a) Human activity in society

From Figure 1, three departments of human activity time presents different trends. Inputs to the primary industry of human activity time declined slightly since 1995 . This reflects present trend of Chinese society's development, more and more farmers and migrant lead to a reduction of human activity time in primary. Human activity time in the second industry and the tertiary industry presents gradually rising trend since 2005. During the period of China's eleventh Fiveyear Plan, Industrial added value increased fiercely.

\section{b) Social spending of human activities}

Changing trends of social spending of human activities in Yunnan province are the same with developed countries. In developed countries, social development has had a rapid development period, this parameters show a growing trend. Although Yunnan's economy is still in development, the rapid development of tourism industry in Yunnan province resulted in high proportion of tertiary industry in all human activities.

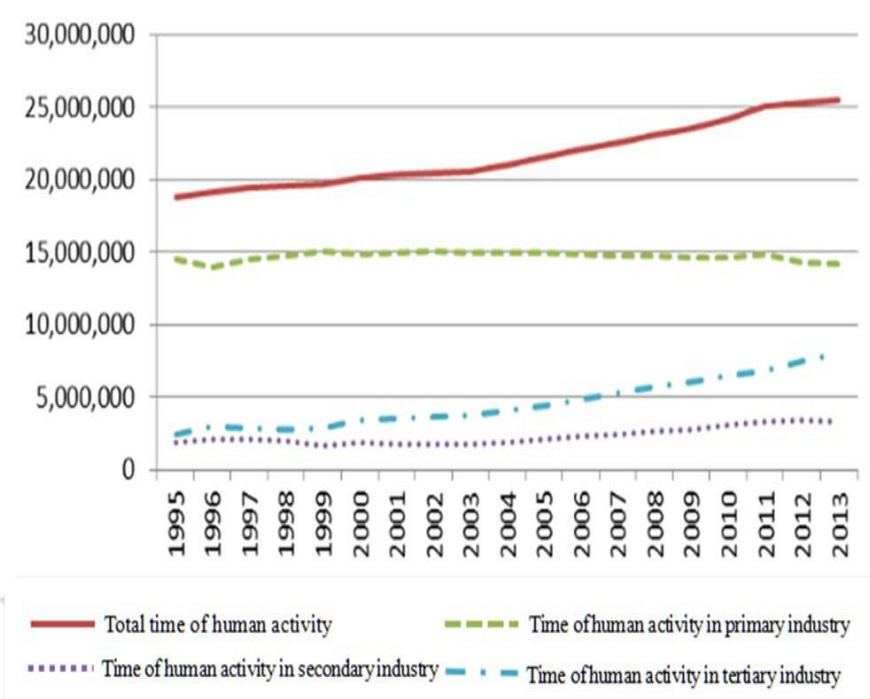

Fig. 1. Human activity time of different industry in Yunnan province

\section{2) Exosomatic energy throughput}

a) Exosomatic energy throughput in each industry

In Figure 2, exosomatic energy throughput maintains a stable growth trend in all three industries, especially in secondary industry.

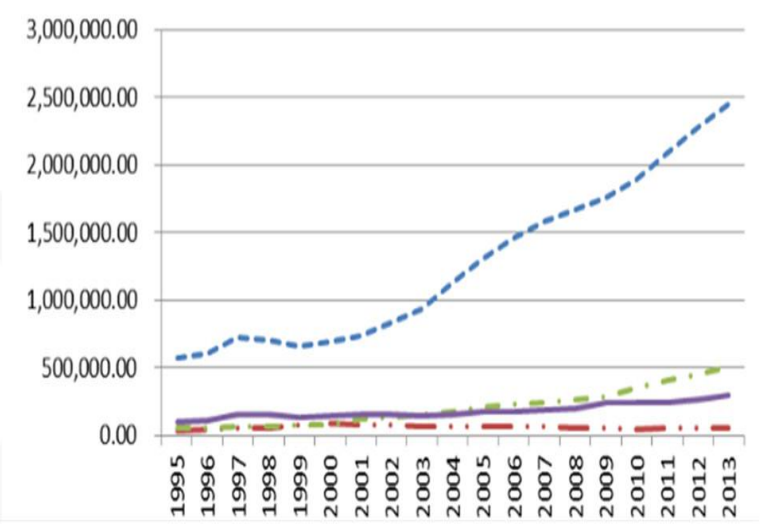

- Exosomatic metabolic of Residents living consumption - - Exosomatic metabolic of primaryindustry

Fig. 2. Exosomatic metabolic of each industry in socio-economic systems

Figure 3 shows that the primary industry volatility is the largest, it shows that the technology of primary industry still needs improvement. Tertiary industry is second only to the primary industry in fluctuation ratio of exosomatic energy, and have sustained growth since 2000, which present the rapid development of tertiary industry in Yunnan province. Exosomatic metabolism in Secondary industry are most stable. The exosomatic metabolism of residents living consumption present periodic fluctuations, which indicate the people's living standards continue to improve. From the whole society, exosomatic energy throughput maintained a stable growth since 2000. After 2005 years the exosomatic energy 
throughput with low growth in Yunnan province, which illustrate the achievements of society to reduce energy consumption.

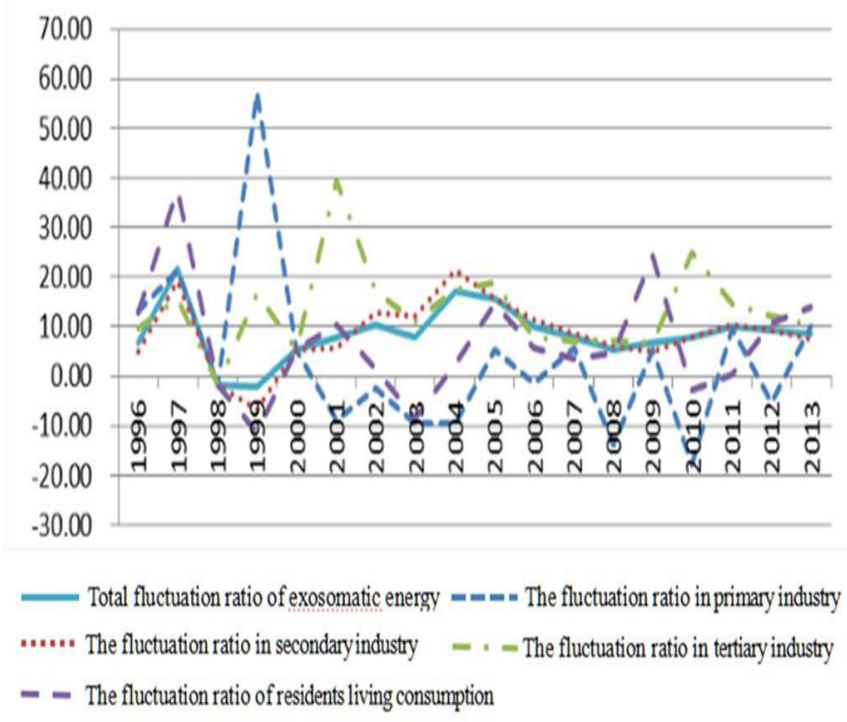

Fig. 3. The fluctuation ratio of exosomatic energy in each industry

\section{b) Exosomatic metabolic rate in each industry}

Exosomatic metabolic rate of the whole society to maintain the steady growth, illustrating that the social level of technical coefficients and capitalization levels keep growing. In 2015, the exosomatic metabolic rate of the whole society is $131,000 \mathrm{~kJ} / \mathrm{h}$, about 3 times of it in 1995. In Yunnan province, the exosomatic metabolic rate of primary industry and the tertiary industry are still at a low level. Secondary industry in the exosomatic metabolic rate are already at a higher level, on the one hand illustrate the progress of industrial technology, on the other hand the industrial department energy consumption intensity, in the process of social development in the future, reduce the rate of secondary metabolism in the exosomatic, is the problem in the circular economy in Yunnan province.

\section{3) Relevant parameter of Value added throughput}

From the trend of value added change in the figure 4 , we can see the value added in primary industry remained relatively stable, and range of growing so small every year. The growth trend of the secondary industry and the tertiary industry is basically the same, which maintained a steady and fast growth. These illustrated general trend of the economic development of Yunnan province that the Second industry and the tertiary industry have rapid development and maintain stable trend in primary production.

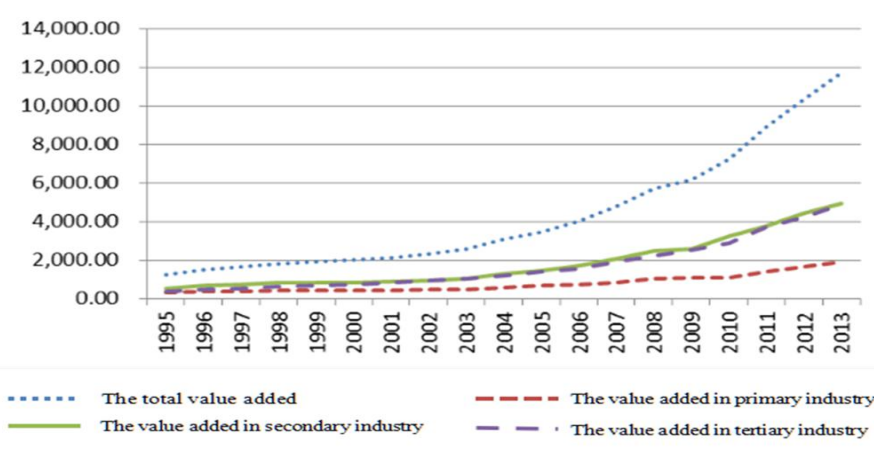

Figure. 4. Value added in each industry

\section{CONCLUSION}

Energy and environment has become a global two challenges. Along with the industrialization in Yunnan province, energy constraints on economic development of Yunnan province become obvious. We conclude from the above analysis as follows:

First, the multi-scale integrated analysis of societal metabolism can assess the sustainability of socio-economic development objectively and systematically of Yunnan province. Differs from the method of statistical indicators to evaluate the energy consumption, the MSIASM from the inherent characteristics of the development of social metabolism in various energy characteristics, get the results from multiple types, and focuses on the features of socioeconomic system, make a more in-depth study.

Secondly, from the economic, social and environmental aspects of the empirical results show that in Yunnan province, about the human activity time and the exosomatic energy throughput, the secondary industry is still in the first place. Rapid development of the tertiary industry alleviate environmental problems have some impact, but the index is still have a gap with developed countries. Overall, the economic sustainability of Yunnan province is well, but in the long term, there is needs for all industries make some adjustment in human activity time and exosomatic energy.

\section{ACKNOWLEDGMENT}

The authors thank other members of the research group for helpful, valuable, and constructive comments and suggestions on earlier versions of this paper. The paper is supported by the National Natural Science Foundation of China (No.71663057), Science Foundation and Major Project of Educational Committee of Yunnan Province (No. 2014Z102).

\section{REFERENCES}

[1] T. GEMIERO, and M. GIAMPIETRO, "Multiple-scale integrated analysis of farming systems. Population and Environment," 2001, pp. 315-352.

[2] N. Georgescu-Roegen, and R.N. Georgescu, "The Entropy Law and the Economic Process," Harvard University Cambridge, 1971. 
[3] M. Giampietro, and K.A. Mayumi, "dynamic model of socio-economic systems based on hierarchy theory and its application to sustain-ability," Structural Change and Economic Dynamics, 1997, pp. 53 -69.

[4] M. Giampietro, and K. Mayumi, "Multiple-scale integrated assessment of societal metabolism:Introducing the approach,Population and Environment," 2000, pp. 109 -153.

[5] M. Giampietro, K Mayumi, S.G.F. Bukkens, "Multiple-scale integrated assessment of societal metabolism: an analytical tool to study development and sustainability, Environment, Development and Sustainability," 2000, pp. 275-307.
[6] United States by Haberl and colleagues, "Theoretical and Practical considerations on the meaning and usefulness of traditional energy analysis," Journal of Industrial Ecology, 2006, pp. 173-185.

[7] M. Giampietro, K. Mayumi, J. Ramos, "Integrated Analysis of Societal and Ecosystem Metabolism(Musiasem):Theoretical Concepts and Basic Rationale," Energy, 2009, pp. 313-322

[8] J.M. Ramos, "Historical analysis of energy intensity of Spain: from a conventional view to an integrated assessment," Population and environment, 2001, pp. 281-313. 